\title{
Olhar ecológico sobre a mediação no processo de inclusão na educação infantil
}

\author{
Ecological look at mediation in the process of \\ inclusion in childhood education
}

\section{Mirada ecológica de la mediación en el proceso de inclusión en la educación infantil}

\author{
Carla Coutinho Moser ${ }^{1}$ \\ Narjara Mendes Garcia ${ }^{1}$ \\ Priscila Wally Chagas ${ }^{1}$
}

DOI: http://dx.doi.org/10.20435/serie-estudos.v26i56.1274

\begin{abstract}
Resumo: O presente estudo constitui-se parte da dissertação de mestrado do Programa de PósGraduação em Educação Ambiental (PPGEA) da Universidade Federal do Rio Grande (FURG). Tem o objetivo de conhecer e compreender os processos de intervenções em crianças com Transtorno do Espectro Autista (TEA) inseridas na Educação Infantil em territórios ecológicos distintos, identificando as percepções sobre a formação dos educadores e as políticas educacionais direcionadas para esse público. O trabalho teve como proposta utilizar a metodologia da Inserção Ecológica nos contextos escolares que atendem crianças com TEA, com idades de 0 a 5 anos, de forma qualitativa, em contextos sociais diferentes. Os resultados apontam para diferenças e proximidades no trabalho pedagógico realizado pelas professoras no Brasil e em Portugal. Diante disso, é importante que tenhamos o conhecimento da necessidade de intervenção e educação especializadas, para minimizar os sintomas que prejudicam esse trabalho pedagógico e oportunizar uma melhor qualidade de vida para os indivíduos com TEA.
\end{abstract}

Palavras-chave: educação ambiental; intervenção precoce; transtorno do espectro autista; formação de professores.

Abstract: The present study is part of the master's thesis of the Graduate Program in Environmental Education (PPGEA) of the Federal University of Rio Grande (FURG). The purpose of this study is to understand the processes of intervention with children who have Autism Spectrum Disorder (TEA) inserted in Early Childhood Education in distinct ecological territories, identifying education perceptions from educators and educational policies directed to this public. The purpose works are to use the Ecological Insertion methodology in school contexts that attend children with TEA, from aged 0 to 5 years, in a qualitative way, in different social contexts Brazil and Portugal. The results point to differences and proximity in the pedagogical work carried out by teachers

1 Universidade Federal do Rio Grande (FURG), Carreiros, Rio Grande do Sul, Brasil. 
in Brazil and Portugal. Given this, we must be are aware of the need for specialized intervention and education to minimize the symptoms that impair this pedagogical work and provide a better quality of life for individuals with TEA.

Keywords: environmental education; early intervention; autism spectrum disorder; teacher training.

Resumen: Este estudio es parte de la disertación de maestría del Programa de Postgrado en Educación Ambiental (PPGEA) de la Universidad Federal de Rio Grande (FURG). Tiene como objetivo conocer y comprender los procesos de intervención en niños con Trastorno del Espectro Autista (TEA) insertados en Educación Infantil en diferentes territorios ecológicos, identificando las percepciones sobre la formación de educadores y las políticas educativas dirigidas a este público. El trabajo tuvo como propuesta utilizar la metodología de la Inserción Ecológica en los contextos escolares que atienden a niños con TEA, con edades de 0 a 5 años, de manera cualitativa, en diferentes contextos sociales. Los resultados apuntan a diferencias y similitudes en el trabajo pedagógico realizado por los docentes en Brasil y Portugal. Por ello, es importante que seamos conscientes de la necesidad de una intervención y educación especializada, para minimizar los síntomas que dificultan esta labor pedagógica y brindar una mejor calidad de vida a las personas con TEA.

Palabras clave: educación ambiental; intervención rápida; desorden del espectro autista; formación de profesores.

\section{INTRODUÇÃO}

A Educação Infantil mostra-se como uma etapa da educação importante para promover o desenvolvimento infantil de forma global e lúdica. Diante disso, a criança com Transtorno do Espectro Autista (TEA) ou com possível risco de manifestar o transtorno se desenvolverá melhor quando inserida o mais cedo possível na escola, por meio de intervenções adequadas e necessidades específicas que necessita.

Pensar em mediação pedagógica para a inclusão na Educação Infantil denota a necessidade de pensar na qualidade da educação para as crianças com TEA. Uma escola com pouca preocupação na formação continuada de seus educadores poderá apresentar uma baixa qualidade no atendimento e não contribuir de forma efetiva no desenvolvimento dos sujeitos, ocasionando mais deficit nas aprendizagens. A formação para os educadores auxilia a não ter um olhar reducionista ao processo de inclusão, como também passar a olhar e considerar os contextos ecológicos que o indivíduo está inserido e compreendê-los de forma sistêmica.

As crianças com TEA são expostas à situação de vulnerabilidade socioambiental quando privadas da convivência entre seus pares e de beneficiar-se de experiências significativas proporcionadas pela escola de Educação Infantil. 
Assim, a intervenção precoce na primeira infância evita a exclusão social das crianças com TEA, contribuindo com o sentimento de pertencimento nos seus contextos de desenvolvimento e sua integração e participação na sociedade. E, para efetivar a inclusão, a organização do espaço e tempo da escola, bem como as atividades propostas, precisa facilitar a expressão, a comunicação e as aprendizagens por meio do uso de rotinas no cotidiano, ao antecipar o que acontecerá, materiais concretos e dicas visuais, de acordo com as especificidades de cada criança.

As identificações dos sinais do TEA em crianças costumam ser percebidas durante os 12 a 24 meses de vida, porém podem ser observados antes desse período se os atrasos se manifestarem mais graves. A criança pode apresentar perdas de habilidades no curso do desenvolvimento aparentemente típico que regride (autismo regressivo), sendo raras em outros transtornos. O TEA “[...] é diagnosticado quatro vezes mais frequentemente no sexo masculino do que no feminino" (APA, 2014, p. 53). Logo, os sinais do transtorno tornam-se passíveis de observação já no começo da infância, necessitando profissionais atentos e qualificados para o diagnóstico.

Conjetura-se que a situação de crianças com TEA e de suas famílias, no Brasil, pode ser ainda mais difícil do que a daquelas que vivem em países norte-americanos ou europeus, de onde provêm os achados da maioria das pesquisas sobre o tema. Reconhece-se que uma parcela muito pequena da nossa população é diagnosticada antes dos três anos de idade, e isso, na maioria das vezes, se restringe aos grandes centros onde existem especialistas na área. Assim, presume-se que famílias com baixo nível socioeconômico e que residem em cidades pequenas do interior dos Estados têm formas muito limitadas de acessar uma orientação profissional especializada. (BACKES; BOSA; ZANON, 2017, p. 155).

Em crianças pequenas com TEA, as dificuldades nas interações sociais e comunicativas podem ser um obstáculo para as aprendizagens por meio das atividades com outras pessoas. As dificuldades exageradas com as mudanças de rotina, principalmente quando imprevisíveis, podem gerar respostas negativas, levando a situações extremas. São constantes as dificuldades motoras percebidas por meio da falta de coordenação, caminhar na ponta dos pés e marcha diferente. É também comum ocorrer autolesão e comportamentos desafiadores (APA, 2014). 
As dificuldades com a comunicação e interação social podem ser percebidas por pouco ou nenhum contato ocular, comprometimento na interpretação das expressões faciais e pouca ou nenhuma compreensão das sutilezas comunicativas. Também, podem apresentar isolamento social ou comportamento inapropriado que pareça agressivo. As crianças pequenas apresentam falhas na imitação social, nas brincadeiras de faz de conta, não utilizam o brinquedo de forma funcional e têm insistência em regras fixas. Os interesses restritos e repetitivos podem ser percebidos pelas estereotipias (ex.: balançar as mãos, piscar os olhos), uso repetitivo de objetos (girar ou enfileirar objetos) e por meio da fala repetitiva ecolálica, quando a criança repete imediatamente o que ouviu, ou fala (ecolalia tardia) de outros momentos que escutou (APA, 2014).

A Lei n. 12.764/2012, que institui a Política Nacional de Proteção dos Direitos da Pessoa com Transtorno do Espectro Autista (TEA), conhecida como Lei Berenice Piana, é uma conquista por meio das lutas de uma mãe que mobilizou o país, para reconhecer os indivíduos com TEA como pessoas com deficiência para todos os efeitos legais. Por meio da sanção da referida lei, foram garantidos diversos direitos e acessos a serviços, a qualificação destes para melhor atender essa especificidade e, também, a proteção contra qualquer forma de abuso e exploração que possam sofrer. Essa medida garantiu apoio especializado e adaptações necessárias para que tenham uma igualdade de oportunidades, bem como incentivo por parte das instituições de ensino à formação e capacitação dos profissionais.

As Diretrizes Curriculares Nacionais da Educação Infantil (DCNEI) orientam que a proposta pedagógica para Educação Infantil deve contemplar "[...] condições e recursos para que as crianças usufruam seus direitos civis, humanos e sociais" (DCNEI, 2010, p. 17). E, como a referida diretriz aponta, a instituição de educação precisa oferecer "[...] acessibilidade de espaços, materiais, objetos, brinquedos e instruções para as crianças com deficiência, transtornos globais de desenvolvimento e altas habilidades/superdotação" (p. 20).

A escola de Educação Infantil mostra-se para as crianças como uma possibilidade de incentivar as relações sociais, principalmente por interagir com outras pessoas que não pertencem ao vínculo familiar e por relacionar-se com outros sujeitos da mesma idade. No entanto, o processo de inclusão nas escolas ainda é difícil para as famílias, apesar da referida lei já mencionada, que garante direitos específicos para matrículas na escola regular para quem tem 
autismo. O preconceito aparece de forma velada, com o argumento de que não há vagas, profissionais qualificados ou ambiente adaptado, mesmo sendo crime negar vaga. As famílias escutam tantas escusas/desculpas, que a maioria acaba se desestimulando. Logo, é necessário refletir como fica o direito de todas as crianças de frequentarem a escola.

A inserção na escola das infâncias de crianças com TEA pode contribuir, também, para desconstruir pensamentos sobre o referido transtorno e construir outras concepções sobre a criança com deficiência, passando a considerar diferentes manifestações e interações nas infâncias, ao privilegiar o sujeito criança, e não o diagnóstico que tem, o qual the impõe a uma situação de incapaz. 0 atendimento precoce não pode ser compreendido unicamente pela "[...] vertente da reabilitação, da intervenção psicossocial ou da educação. Todavia, deve fazer parte de um processo integral que tem como fim último o desenvolvimento harmônico de crianças integradas aos contextos em que vivem" (BOLSANELLO; SOEJIMA, 2012, p. 65).

A pesquisa realizada teve por objetivo conhecer e compreender os processos de inclusão de crianças com TEA na Educação Infantil em contexto luso-brasileiro, identificando-se as percepções sobre a formação dos professores e as políticas educacionais direcionadas para esse público.

\section{ESTRATÉGIAS METODOLÓGICAS PARA PESQUISA EM DOIS TERRITÓRIOS DISTINTOS}

A pesquisa teve como metodologia a Inserção Ecológica (CECCONELLO; KOLLER, 2004), com o objetivo de conhecer e compreender os processos de inclusão de crianças com Transtorno do Espectro Autista na Educação Infantil em territórios ecológicos distintos, identificando-se as percepções sobre a formação dos professores, a inclusão da criança com o TEA e as políticas educacionais direcionadas para esse público.

Para isso, a pesquisa teve como base a Teoria da Bioecologia de Desenvolvimento Humano de Bronfenbrenner (1979/1996), para compreender de forma "ecologicamente contextualizada" as articulações e interações que são estabelecidas nos microssistemas dos sujeitos, ou seja, entre as crianças e os seus educadores, a família com a escola, com os objetos e símbolos e nas relações 
que se constituem face a face. Do mesmo modo, a importância dos estudos reformulados que resultaram no modelo bioecológico do desenvolvimento humano (BRONFENBRENNER; MORRIS, 1998) com a interação de quatro elementos inter-relacionados: o processo, a pessoa, o contexto e o tempo (PPCT), em que o processo de inserção ecológica se fundamenta.

A escolha da metodologia de Inserção Ecológica justifica-se por proporcionar ao pesquisador uma maior aproximação com a realidade a ser analisada, possibilitando um olhar ecológico sobre o ambiente.

O modelo ecológico proposto por Bronfenbrenner (1979/1996) é composto pela interação de quatro níveis ambientais, denominados: microssistema, mesossistema, exossistema e macrossistema. No presente estudo, foi analisado o microssistema escolar por meio da escola da infância, como apontam Lisboa e Koller (2004, p. 17): “O microssistema escolar é um espaço para o desenvolvimento intelectual, social, emocional e moral". Nesse sentido, é relevante destacar a importância da escola como um ambiente promotor de desenvolvimento para as crianças com TEA, além de sua relevância no processo de inclusão social.

Para caracterizar o modelo PPCT e realizar a metodologia da inserção ecológica, foi necessário que a base da investigação ocorresse no ambiente imediato com a interação do pesquisador, dos participantes, objetos e símbolos nos dois territórios.

A metodologia da Inserção Ecológica compreende um novo modo de perceber o contexto dos sujeitos, envolvendo todas as características que compõem o ambiente em que está inserido. A intenção foi utilizar a observação naturalística, eliminando a separação entre sujeito e o objeto de pesquisa, com registro em diário de campo, como também entrevistas reflexivas com os professores da infância das crianças com TEA.

O primeiro território de inserção para pesquisa foi no contexto português na cidade de Braga, localizada na região Norte de Portugal. A inserção durante esses 30 dias no país permitiu-nos conhecer os espaços e tempos em nível macro e de microssistema na Educação Infantil, o que é proporcionado para as crianças, as metodologias que influenciam a organização do ambiente e que refletem nos comportamentos das crianças. As impressões dos professores sobre o processo de inclusão das crianças com TEA e a interlocução com o sistema de intervenção precoce puderam ser analisadas sob um olhar ecológico. 
Dentro das salas de aula, todas têm uma estrutura de organização por ambientes de aprendizagem, como High Scope e Escola Moderna, com muitos brinquedos e materiais sinalizados e de fácil acesso para as crianças. Além disso, as salas têm os murais, em que as crianças decidem e escolhem os ambientes que querem interagir no dia. No final, são responsáveis pela organização dos materiais.

As professoras participantes têm formações em nível de pós-graduação, três educadoras com mestrado em Educação Especial e todas com formações continuadas sobre inclusão. As profissionais são titulares de turmas de pré-escola, com grupos constituídos por um mínimo de 20 e um máximo de 25 crianças. Algumas turmas tinham número reduzido por causa da inclusão das crianças com Necessidades Educativas Específicas, mas todas tinham uma ou duas auxiliares na sala de aula, dependendo da mantenedora.

No contexto brasileiro, a pesquisa foi realizada na cidade do Rio Grande, Rio Grande do Sul, e tentou-se seguir o mesmo critério de Portugal, utilizando o critério por indicação. Para tal, buscou-se como referência uma escola de Educação Especial, especializada em atendimentos a pessoas com o TEA, em que foram indicadas cinco professoras que atendem as crianças nas escolas de Educação Infantil do município e nessa instituição, concomitantemente, em contraturno. Todas aceitaram fazer parte deste estudo.

A escola de educação especial especializada em atendimento a pessoas com TEA utilizada como critério para a pesquisa atende estudantes nas modalidades: complementar, para as crianças que estão nas escolas de ensino regular; e suplementar, para os casos mais graves, em que a família escolhe ser a única instituição de educação para atender o estudante. A escola desenvolve o trabalho com base nos programas TEACCH (Treatment and Education of Autistic and related Communication-handicapped Children) e ABA (Applied Behavior Analysis), e atende crianças a partir dos 4 anos. O programa TEACCH teve sua origem em 1971, por Eric Schopler e outros colaboradores americanos, para o tratamento e a educação para as pessoas com TEA de todas as idades, desenvolvendo atividades com a organização da rotina, tarefas estruturadas, comunicação alternativa, sinalização visual e controle do comportamento (CIOLA; FONSECA, 2014). O modelo ABA é aplicado por meio de princípios básicos da análise de comportamento, conduzindo para comportamentos socialmente relevantes e diminuindo os comportamentos problemáticos. 
Os espaços físicos das salas de aula visitadas estão necessitando de reforma e de mais brinquedos e jogos para as crianças interagirem, pois o que percebemos é que existe uma grande precariedade desses, e alguns materiais são de sucata.

As professoras participantes têm formações em nível de pós-graduação, duas delas com especialização em Educação Especial, três somente com ensino superior. As educadoras são titulares das turmas de pré-escola, com grupos constituídos por uma quantidade mínima de 13 e um máximo de 15 crianças, número reduzido por causa da inclusão das crianças com o TEA. Todas as turmas têm auxílio do monitor de inclusão.

Para a pesquisa, utilizaram-se entrevistas com as professoras das crianças com TEA nos dois contextos de estudo, Brasil e Portugal, nos ambientes de trabalho dos entrevistados. Essa conversa apresentou-se como um importante meio de entendimento para compreender os entrelaçamentos que norteiam as questões de pesquisa.

Para melhor situar os dados coletados por meio das informações obtidas pelo diário de campo, observações naturalísticas e das entrevistas reflexivas, foi utilizada a Teoria Fundamentada nos Dados (TFD) (CHARMAZ, 2009), desenvolvida por Glaser e Strauss, em 1967. A referida metodologia de análise dos dados é qualitativa e mostra-se relevante para compreender o processo das experiências dos educadores. A TFD apresenta diretrizes para explicar os caminhos pesquisados, com maior precisão e rigor científico.

A inserção e a coleta de dados deram-se ao longo do ano de 2018, no espaço de tempo entre janeiro e outubro de 2018, nos dois territórios, totalizando dez entrevistas e oito instituições de Educação Infantil visitadas.

\section{O PROCESSO DE INCLUSÃO NA EDUCAÇÃO INFANTIL NO BRASIL E EM PORTUGAL}

No estudo realizado sobre a criança com o Transtorno do Espectro Autista (TEA) e as intervenções dos professores em contextos sociais distintos, optou-se por perceber como os professores utilizam estratégias educacionais que favorecem o desenvolvimento das crianças com o transtorno na Educação Infantil, sob o olhar ecológico, como também compreender o processo de inclusão no contexto escolar, as políticas e teorias que orientam as práticas com as crianças com TEA na Educação Infantil. 
Foi possível constatar que tanto no Brasil quanto em Portugal existe uma preocupação em tornar a escola um ambiente inclusivo, por meio do avanço e das alterações nas políticas educacionais. A educação inclusiva ainda é um desafio, vários problemas são apontados pelas participantes, no entanto há um esforço para que se efetive o direito de todas as crianças a terem acesso à escola e, assim, não deixar ninguém de fora.

Ao analisar as entrevistas das professoras dos dois contextos distintos, foi possível perceber que há experiências positivas e ainda algumas dificuldades diante do processo de inclusão da criança com o TEA na Educação Infantil. Ao longo dos relatos das participantes, é possível realizar reflexões e indicar possíveis estratégias de intervenções para uma inclusão ecológica, por meio das contribuições de Bronfenbrenner $(1996 ; 2011)$ e outros autores que dialogam com essa proposta. $\mathrm{Na}$ inclusão ecológica, o sujeito é percebido como ativo em um processo recíproco com o ambiente em que está inserido.

Para compreender o processo de inclusão da criança com o TEA na Educação Infantil, buscou-se trazer um pouco das questões que envolvem o diagnóstico e os saberes das professoras sobre os sintomas que podem estar presentes no transtorno, para construir estratégias e adaptações necessárias no ambiente escolar. Ter o olhar ecológico envolve o professor olhar para essa criança em sua totalidade, conectando um trabalho em rede com outros contextos e educadores e não se esquecendo de que, atrás do diagnóstico, existe uma criança, a qual necessitará de uma atenção maior ao transitar pelos microssistemas, da sua chegada à escola de Educação Infantil até sua trajetória para o primeiro ano.

Assim, no seguimento, serão apresentadas algumas das categorias que emergiram a partir da análise das percepções das professoras de Educação Infantil de crianças que têm o TEA no território luso-brasileiro.

\section{O TRABALHO PEDAGÓGICO E A MEDIAÇÃO DO PROFESSOR PARA A CONSTITUIÇÃO DE UM CONTEXTO ECOLÓGICO DE INCLUSÃO}

Ao se pensar nos processos de mediação do professor que vão ao encontro da inclusão, requer-se um olhar atento para as singularidades de cada criança, como também a promoção de experiências que "[...] teçam o conhecimento por fios coloridos, que expressem diferentes possibilidades de interpretação e de 
entendimento de um grupo de pessoas que atuam cooperativamente" (MANTOAN, 2015, p. 78).

Durante o processo das análises das entrevistas dos dois contextos pesquisados, Brasil e Portugal, foi possível perceber que algumas participantes se sentiam angustiadas, relatando as dificuldades de trabalhar com crianças com TEA, porém, ao mesmo tempo, mostravam-se entusiasmadas em querer buscar estratégias para qualificar o trabalho e a inclusão da criança na escola. Como aponta a professora portuguesa Aline, "É muito difícil trabalhar com eles, depois há aquele medo de que há professores que põem em prática e outros não porque não querem se chatear" (Aline, 2018, Portugal). Os professores que realizam esforços durante um ano letivo, para potencializar o desenvolvimento da criança, mostram-se receosos com os próximos colegas que receberão a criança, que talvez não tenham o mesmo empenho e dedicação.

Há uma vontade de fazer a diferença, ou seja, mesmo não sabendo como lidar com uma criança com deficiência, não há motivo para não tentar melhorar o ambiente para que a criança possa se desenvolver com seus pares. Como denota a professora brasileira Beatriz: "Sou bem crua ainda, fico nervosa, eu só tenho a boa vontade" (Beatriz, 2018, Brasil). De acordo com Mantoan (2015, p. 78), "[...] um professor que participa da caminhada do saber com os alunos consegue entender melhor as dificuldades e possibilidades de cada um".

Outra característica comum nos dois territórios pesquisados, relatada pelas participantes, é a necessidade do uso da rotina para criança com TEA e o fato de que, conjuntamente, toda a turma beneficia-se disso. No entanto observa-se que, no contexto brasileiro, as professoras ainda têm dificuldades em termos de como utilizar a rotina visual e a criança com TEA beneficiar-se desta, bem como estruturar e organizá-la. "Fazemos a rotina que utilizamos para todos, que são fotos aleatórias da internet, estamos pensando em mudar porque estamos achando que, para ele, tem certas figuras que ele não está identificando, mas não sabemos como" (Geane, 2018, Brasil).

Comecei então a estruturar a rotina, pois percebia que ele não entendia a rotina, mas estruturei para toda turma. Precisei fazer uma rotina real, com objetos concretos durante dois anos. E então começamos a alterar de propósito a rotina, porque ele tinha aversão às mudanças, para ir se ambientando, porque sabemos que no dia a dia não pode ser sempre igual, sobretudo em 
casa. No segundo ano, já tinha imagens na rotina para se guiar e já tinha noção do que iria acontecer. (Aline, 2018, Portugal).

A percepção da professora portuguesa de que a criança não compreendia a rotina e as imagens que eram utilizadas por todas as crianças que constituíam a turma foi essencial para reestruturar o ambiente de outra forma, antecedendo ainda a leitura de imagens, que foi a utilização de objetos concretos utilizados na rotina e que passaram então a sinalizar as atividades. São observações que, de acordo com a teoria bioecológica, afetam o desenvolvimento das pessoas no ambiente, pois podem instigar ou desanimar as reações dos sujeitos e seu processo de crescimento (COPETTI; KREBS, 2004). "Ele não possui uma rotina rígida, mas oriento e introduzi uma rotina, com atividades a seguir para toda a turma. O mural fica com o relógio adaptado com a rotina a seguir; se Matheus fosse mais grave, teria que ter um mural diferenciado e mais interativo" (Suelen, 2018, Portugal).

Segundo a educadora, a criança permanecia muito ansiosa para saber a hora do término das atividades e ir para casa, então fez uma adaptação no relógio, com o uso de bolinhas de massa de modelar; quando o ponteiro pequeno do relógio estiver no número 9 (bolinha grande), é o momento de chegada na escola, e quando estiver no número 5, hora da saída (bolinha menor). Segundo a professora, a criança passou a compreender a rotina e diminuir o comportamento ansioso. De acordo com a teoria bioecológica, o tempo de intervalo entre as atividades propostas pode fortalecer ou enfraquecer as disposições pessoais para envolver-se (COPETTI; KREBS, 2004). Por isso é necessária uma rotina que contemple as necessidades da criança e suas características; no caso acima, a criança entra e sai em horários também diferenciados, mas com outros colegas junto, pois uma hora antes e uma depois é considerado horário expandido na instituição, ficando assim para ele saber que alguns colegas ainda ficaram mais um tempo na escola.

No contexto brasileiro, as professoras utilizam também murais com a rotina, porém menos estruturados e com as ordens das atividades mais confusas para as crianças com TEA se organizarem no tempo. Na fotografia 2, percebe-se que não há espaço suficiente para prender todos os cartões da rotina e que a decoração dos prendedores também pode atrapalhar a visualização da atividade a seguir. Na fotografia 3, as palavras poderiam estar em letras maiúsculas (de fôrma) e as figuras que representam as atividades poderiam estar em uma sequência a ser 
executada, pois lado a lado fica confuso. Nesses dois exemplos, antes de serem apresentados para as crianças, há necessidade de saber se a criança identifica imagens para ter sentido em sua rotina. Caso contrário, é preciso buscar alternativas para que a criança possa compreender.

Ao realizar análise sobre as metodologias de trabalho, Portugal apresentou mais opções diferentes de metodologias de trabalho, sendo que essas vão ao encontro de uma proposta que facilita a organização e interação das crianças com TEA no ambiente. As metodologias mencionadas nas entrevistas e percebidas nos contextos foram: High/Scope, DENVER, alguns recursos do TEACCH e pedagogia de projetos, sendo que algumas delas são utilizadas juntas.

Algumas escolas portuguesas estão utilizando a metodologia High/Scope, que surgiu nos anos 1960 nos Estados Unidos e se baseia em um modelo estruturado na organização com os estudantes. Essa organização possibilita aos professores a adaptação de atividades e interações de acordo com o interesse e as dificuldades das crianças; a aprendizagem passa a ser centrada na criança. Elas podem realizar suas escolhas de acordo com seus interesses (GOMES, 2014).

Esse modelo foi percebido em todos os contextos visitados, pelo menos enquanto organização dos móveis e objetos nas salas de aula. E, em sua teoria, percebe-se que facilita o trabalho com a inclusão, principalmente quando as crianças precisam de um ambiente organizado e estruturado para interagir.

O modelo High/Scope propõe um quadro geral de organização das atividades, adaptado à turma com que se trabalha. "A coisa mais importante que queremos que as crianças aprendam é, provavelmente, que todos somos iguais em muitos aspetos e todos somos diferentes noutros aspetos e que tais diferenças são normais". (BRICKMAN; TAYLOR, 1996, p. 184 apud GOMES, 2014 p. 72).

Uma das professoras portuguesas utiliza a metodologia High/Scope na organização das rotinas de trabalho e a proposta da pedagogia de projetos. Ela denota:

Tenho cartões que sinalizam com os cantos identificados por imagem e número. Tem um quadro das presenças com um velcro e eles põem o nome e a imagem para onde vão. Isso facilita para ela e para os outros, ela faz todas as atividades que os outros. (Joana, 2018, Portugal).

A rotina nesse modelo tem flexibilidade e permite à criança organizar seus espaços de aprendizagem e antecipar aquilo que se passará em cada momento 
do seu dia, transmitindo segurança e confiança com o ambiente. Por meio da organização dos espaços e da rotina visual no mural, tende a facilitar a organização das crianças com o TEA, visto que as sinalizações visuais estão presentes nesse modelo. Porém é necessário ter cuidado para que a criança que tem apego a rotinas não vá sempre para as mesmas áreas de interesse; o ideal é que essas áreas sejam ampliadas em seu repertório.

Ainda na mesma sala de aula, a professora utiliza uns relógios e, abaixo, fotografias de cada momento a ser realizado; quando chega a hora de utilizar as áreas de aprendizagem, passam a utilizar o mural de baixo, que foi escolhido pelas próprias crianças, de acordo com seus interesses.

Os brinquedos estão sinalizados nas suas respectivas caixas que os organizam, facilitando a identificação e o acesso ao buscar um brinquedo, bem como no momento de término da atividade, para guardá-lo. As sinalizações auxiliam nas rotinas, conforme destaca a professora: "Nós propúnhamos uma rotina, o esquema do dia com imagens para ele se orientar nos sítios, no refeitório, na casa de banho, pois quando dizíamos vamos lavar as mãos ele ficava a olhar para nós, e para fazer xixi também" (Aline, 2018, Portugal).

A maioria das crianças com o transtorno tem deficits na compreensão da linguagem e dificuldade para lidar com instruções complexas, de processar de forma global as informações, o que aumenta a ansiedade e os comportamentos disfuncionais. E, quando expostos visualmente, de forma ordenada, os passos a seguir, conseguem compreender os fatos e executar melhor, criando oportunidades de aprendizagem. Como denota a professora: "Se ela tem que desenhar, pintar e recortar, tem que dar os passos de cada vez, uma etapa de cada vez" (Joana, 2018, Portugal).

Quando a rotina é livre, ou seja, a criança não tem orientação da atividade a seguir, tende a envolver-se com suas estereotipias, isolamento e outros problemas de comportamento, por ficarem ociosas. Logo, não quer dizer que sistematizar uma rotina piorará as dificuldades em superar mudanças e tornará a criança ainda mais rígida, ao contrário disso, a rotina tem a intenção de promover a compreensão sobre as atividades de seu cotidiano, e as mudanças dentro da própria estrutura auxiliam a superar as alterações que ocorrem em nosso dia a dia (JULIO-COSTA, 2018). 
As escolas onde ocorreram as entrevistas em Braga, no território de Portugal, têm as mesmas organizações, são estruturadas da mesma metodologia de áreas ou cantos de aprendizagens, mas com algumas variações. A professora Fernanda afirma: "Eu vou adaptando, vai dependendo do grupo, utilizo a pedagogia de projetos, por vezes um cadinho mais HighScope, vamos variando" (Fernanda, 2018, Portugal). Percebe-se, de acordo com a proposta de cada professor, o uso ou não de metodologias, desde que sejam suficientes para as demandas do grupo, conforme destaca a professora a seguir:

Uso uma rotina todos os dias, com imagens, mas uso um pouco de cada método, Montessori, High Scope, pronto um monte de situação que sejam boas para o grupo e que sejam para a autonomia deles, isso está tudo marcadinho nas capas, nas cadeiras, eles sabem as coisas deles, sabem ir buscar, entendem regras, acho que estão bem acomodadinhos. (Patricia, 2018, Portugal).

No contexto brasileiro, as salas de aula também se assemelham, porém com menos materiais e recursos disponíveis para as crianças. O que para uma criança com TEA talvez seja positivo, pois não têm tantos estímulos visuais, as salas de aula são menos poluídas visualmente.

O Modelo DENVER ${ }^{2}$ de Intervenção Precoce (ESDM) citado por uma professora portuguesa é uma proposta de Intervenção Precoce direcionada a crianças com o TEA, em que várias competências são trabalhadas, divididas por níveis de faixa etária. Tem como base os princípios norteadores da Análise Comportamental Aplicada ( $A B A$ ) e envolve toda a equipe que atua com a criança, pais, escola e outros educadores nos estímulos com a criança. As intervenções tendem a ocorrer nos contextos naturais da criança ou em consultórios também (ROGERS; DAWSON, 2016).

Metodologia DENVER, é o que tenho mais referência, é o que li, fiz uma formação, fui eu e a mãe, há dois anos em Braga, deu-nos uma abertura um cadinho maior de como nós deveríamos trabalhar com eles, na realidade transmitiram mais informações, como é que eles eram, como nós deveríamos trabalhar com eles e o uso de rotinas estruturadas. (Joana, 2018, Portugal).

2 A formação em DENVER em Portugal é mais disseminada e mais acessível em questões de valores; no Brasil, está há pouco tempo e com o custo muito elevado. 
Outra abordagem mencionada pelas professoras do contexto português foi o Programa TEACCH ${ }^{3}$, mais utilizado pelas educadoras da IP no ambiente da sala de aula. No entanto o conceito da metodologia parece um pouco equivocado quanto a sua utilização na sala de aula. O programa tem as iniciais do inglês Treatment and Education of Autistic and Related Communication Handicapped Children, que pode ser traduzido como Tratamento e Educação para Autistas e Crianças com Limitações Relacionadas à Comunicação. Tem o objetivo de, dentro da área psicoeducacional, atender crianças diagnosticadas com o TEA, em busca, preferencialmente, de um comportamento mais autônomo e independente.

Temos um material organizado, que elas usam para trabalhar com ele, o TEACCH, e na sala com ele utilizo a mesma coisa que utilizo com todos, com a educadora de apoio. A terapeuta ocupacional que utiliza as atividades do TEACCH. Agora ela está a trabalhar parte da tríade, né, da motricidade fina, a pegar o lápis, mas a motricidade fina está a ser desenvolvida, a fazer a pinça, a pegar na tesoura, e pronto, basicamente é isso que elas fazem grafismos, sequências e enfiamentos. Estou a tentar implantar que ele identifique o nome dele, as coisas da rotina ele identifica tudo. (Patricia, 2018, Portugal).

No contexto brasileiro, percebem-se alguns princípios do TEACCH nas salas de aula, quanto à sinalização e adaptação de materiais e planejamentos, para que, por meio de um sistema e orientação visual, as crianças possam ter mais autonomia e aprendizagens nas atividades propostas. Esse programa já se apresenta de forma mais comum e possibilita ao professor estruturar o ambiente para a criança com TEA, sendo que as demais também vão beneficiar-se.

E a única metodologia mencionada pelas pesquisadoras brasileiras, por mais que já se observe o uso dos princípios do programa estruturado, foi a pedagogia de projetos, com o uso de recursos visuais e adaptações nos objetivos e na forma de trabalhar com as crianças com o transtorno.

Faço a hora do conto e tem que ser uma história com bastantes imagens, objetos, alguma coisa que chame a atenção dele. Se eu pedir para que os outros se sentem para ouvir, eles vão se sentar, faço adaptações para cha-

\footnotetext{
3 No Brasil, a respeito do programa TEACCH, existe uma grande especialista no assunto, a psicóloga Maria Elisa Granchi Fonseca. A técnica foi originada nos Estados Unidos, registrada de posse da University of North Carolina (UNC), e todos os direitos são reservados. Essa universidade é a única autorizada a instruir pessoas para aplicar as estratégias do programa.
} 
mar a atenção dele. Do contrário, ele não estaria sentado, ele estaria lá na prateleira pegando um brinquedo. (Geane, 2018, Brasil).

Ao observar os discursos das professoras brasileiras, percebe-se uma preocupação em efetivar as interações e os processos proximais entre as crianças, estes são os objetivos principais das diretrizes da Educação Infantil em nosso país e uma das dificuldades das crianças com o TEA. Elaborar estratégias para atrair a atenção da criança é importante, diante da aparente preferência por envolverem-se em atividades solitárias; isso acontece, muitas vezes, justamente por não saberem como engajar-se ao grupo. Conforme destaca uma das participantes da pesquisa, "As adaptações são feitas mais no sentido da apresentação da atividade, para que o aluno entenda o que se espera dele" (Ana, 2018, Brasil).

Sobre os recursos que uso, hoje foi a história da Branca de Neve, eu trago o que tenho em casa, chapéu, uma maçã, espelho, coisas que dá para adaptar para o recurso visual e procuro não usar livro. A Isis não irá atentar para o livro. Fico perdida e no início era pior. Eu sei que ela viu que foi pego o chapéu, a maçã e o espelho, mas saber se ela entendeu a história eu não sei, acredito que alguma coisa ela captou. A mensagem da história os outros entenderam, mas ela eu fico em dúvida. (Beatriz, 2018, Brasil).

Ao analisar o ambiente e todas as possibilidades que este pode promover no desenvolvimento das crianças, principalmente daquelas com o transtorno, é necessário o professor mediar os processos proximais utilizando uma lente ecológica (LISBOA; KOLLER, 2004). Essa lente oportunizará uma visão integral dos sujeitos inseridos no contexto escolar, permitindo ao professor se despir de preconceitos e abrir-se para a diversidade, reavaliando sua própria prática dentro do ambiente.

Os questionamentos, reflexões e avaliações das professoras são muito importantes, pois, antes de concluirmos que a criança não sabe fazer, que não demonstra interesse ou se isola, é necessário pensarmos como estamos propondo as atividades e se a criança entendeu o que estamos esperando dela. A professora Joana aponta: "Eu tenho minhas dúvidas, acho que ela percebe o que estou a dizer, mas nem sempre age. Por isso entro na dúvida, será que ela me compreendeu? Será que não compreendeu?" (Joana, 2018, Portugal).

O trabalho requer um olhar e uma escuta atentos para pequenos sinais comportamentais e de expressões pelos quais a criança comunicará sua relação 
com o ambiente e as pessoas, de forma que o professor, enquanto mediador, possa auxiliar nos processos de desenvolvimento. "O que eu faço é o planejamento e a atividade para ela é adaptada. Estou trazendo coisas visuais e acabo por apresentar a todos. É mais para que ela pegue, toque, se aproxime, desperte a atenção e fique junto" (Beatriz, 2018, Brasil).

Bronfenbrenner e Evans (2000) alertam sobre os riscos e a proteção nos processos proximais no contexto escolar, que podem se caracterizar como competências ou disfunções. A criança com TEA tende a apresentar muitos comportamentos disfuncionais, muitos em razão de não saber comunicar-se e o que fazer no ambiente. Porém esse mesmo ambiente, quando organizado e com objetivos planejados, pode favorecer o desenvolvimento de competências e ganhos de habilidades que modificarão seu comportamento, de forma a impulsionar seu desenvolvimento diante das interações e relações estabelecidas. Cabe o professor buscar os apoios e recursos necessários para mediar esse processo (LISBOA; KOLLER, 2004). Um exemplo de comportamento disfuncional, que, após um período de tempo e mediação, passou a tornar-se funcional pela criança, adquirindo competências necessárias para permanecer no ambiente junto à turma, é da professora a seguir:

Devido às dificuldades dela aceitar o momento do refeitório, comecei a ir um pouco mais tarde e ela foi se acostumando, ela entra e senta. Hoje a monitora observou que ela não esperou que a mesma sentasse para sentar-se no colo. A monitora conseguir sentar e ela sentar-se no colo já é uma vitória, pois ela não queria sentar, ela sentava no chão, são passos que vamos dando. Quando ela começou a ficar no refeitório, era no chão, com as pernas abertas, e comia o lanche sentada no chão, esse foi o primeiro momento, depois ela começou a ficar em pé na cadeira, depois no colo da monitora. E hoje ela puxou a cadeira e sentou-se sozinha. (Beatriz, 2018, Brasil).

A professora teve sucesso aos poucos com o objetivo de a criança sentar-se na cadeira e permanecer no refeitório no mesmo momento que os outros. Mas cabe refletir os motivos pelos quais a criança não queria permanecer no ambiente, sobre o que a deixava ansiosa e agitada. Talvez, com mais sinalizações visuais, ela pudesse ficar mais tranquila ao saber o que aconteceria.

Retomando a importância do olhar da lente ecológica do professor, é preciso primeiramente tornar o ambiente um lugar de significados para a criança com o TEA. É necessário desmistificar o transtorno, com mais informações sobre as 
características para que as pessoas compreendam alguns dos comportamentos e possam assim promover a inclusão.

O primeiro passo foi conversar, eu pedi para a professora da sala de recursos explicar aos pais o que era o autismo, como era e como podíamos auxiliá-los a virem preparados de casa. Para que conversassem com os filhos em casa, foi a professora da sala de recursos que fez essa mediação. Os pais não tinham nenhuma ideia, apenas uma mãe nos surpreendeu, ela tem um irmão ou sobrinho autista já adulto. (Geane, 2018, Brasil).

O TEA precisa ser falado entre a comunidade escolar, conversar com todas as pessoas que estão envolvidas de alguma forma com o contexto da escola sobre os direitos da pessoa com deficiência e a garantia de usufruir dos mesmos espaços que todos têm. Ações pedagógicas de sensibilização são necessárias no início do ano letivo, para que os pais das crianças possam também educar na perspectiva inclusiva, do respeito a qualquer pessoa, independentemente de sua diferença.

[...] depois o problema foi com os pais, porque as crianças iam mordidos, ela arrancava a pele, com hematomas muito grandes nos colegas, e os pais começaram a apontar o dedo. Pois aí os pais começaram a ser sensibilizados, às vezes quando pegava um pai mais sozinho tinha que Ihe chamar a atenção, não é? Porque ninguém está livre. Fiz formações e, nesse momento, não há pai nenhum que aponte o dedo. (Joana, 2018, Portugal).

Seguindo a linha na mediação para inclusão, a mesma professora acima, analisando como poderia oportunizar a participação da criança na hora da assembleia (momento em roda, na chegada), teve a ideia de contar com a participação da família da criança, para que auxiliassem nesse momento também. Então, foi por meio da mediação a seguir:

Segunda-feira de manhã contamos o fim de semana, o que fez, o que gostou, pronto! Ela não verbaliza, então a mãe manda uma fotografia e nós mostramos a fotografia. 'Monica, o que estavas a fazer?'. Claro que às vezes ela não sabe, então a mãe nos diz o que ela fez, aí nós dizemos isto: fui ao shopping, fui a praia, e ela diz. Pronto! Portanto é uma maneira dela também contar o que fez e obrigá-la a e expressar-se, e os pais também, de estarem a trabalhar com ela e se sentem incluídos. (Joana, 2018, Portugal).

Pensar formas de participação na sala de aula para que a criança possa também mostrar seus interesses é focalizar nos processos de interações possíveis 
para aquele grupo, para aquela criança. A visão ecológica é aquela que nos trará uma visão sistêmica do todo, das relações no ambiente, das interações face a face e com os objetos, para poder pensar que estratégias e recursos podem ser utilizados naquele contexto, com aquelas pessoas, naquele tempo, permitindo situações de muito aprendizado (LISBOA; KOLLER, 2004).

Uma das professoras entrevistadas no território brasileiro se lembrou também dos momentos que as crianças se sentam em círculo e da estratégia que utilizou para a criança permanecer junto ao grupo e diminuir a ansiedade. "Quando sentamos em círculo, sempre o coloco do meu lado, senão ele vai ficar no meio querendo olhar o livro primeiro, pois ele fica ansioso para ver, então eu coloco o livro sempre no lado dele e assim ele fica olhando" (Cristina, 2018, Brasil).

Portanto, nos processos de mediação, é imprescindível o professor utilizar essa lente ecológica (LISBOA; KOLLER, 2004), percebendo que a criança com o TEA processa as informações de forma diferente e que, para isso, as características e os processos proximais "[...] abrange[m] formas particulares de interação do organismo com o ambiente [...], que operam ao longo do tempo e são situadas como os mecanismos primários que produzem o desenvolvimento humano" (BRONFENBRENNER, 2011). Logo, o que ocorre no ambiente influenciará no comportamento da criança e em suas aprendizagens. É preciso procurar estratégias e recursos que promovam o desenvolvimento das crianças, favorecendo o processo de inclusão e de pertencimento ao contexto escolar.

\section{CONSIDERAÇÕES FINAIS}

Nos dois territórios pesquisados, Brasil e Portugal, as políticas públicas vêm avançando no sentido de garantir os direitos das pessoas com deficiência e avançando para um olhar sobre a pessoa em desenvolvimento de sentir-se pertencente ao ambiente. Porém existem ainda muitas dificuldades em diminuir os distanciamentos entre o que temos e o ideal, para atender a todas as demandas diante da inclusão.

É necessário mapearmos como estamos nos organizando para acolher as pessoas com deficiência e necessidades educacionais especiais, para que suas dificuldades não sejam vistas primeiro do que elas enquanto pessoas, como também estabelecer e aprimorar a rede de atendimento que temos disponível, seguindo 
exemplos que já são realidade e adaptando ao nosso contexto. De acordo com Mantoan (2015, p. 21):

Um novo paradigma do conhecimento está emergindo das interfaces e das novas conexões que se formam entre saberes outrora isolados e partidos e dos encontros da subjetividade humana no cotidiano, o social, o cultural. Redes cada vez mais complexas de relações, geradas pela velocidade das comunicações e informações, estão rompendo as fronteiras das disciplinas e estabelecendo novos marcos de compreensão entre as pessoas e do mundo em que vivemos.

Durante as análises das entrevistas, ficou evidente a necessidade de olharmos para o outro independentemente do seu diagnóstico e perceber quem ele é, quais suas dificuldades, potencialidades e como os educadores podem contribuir para sua vida. Novas perspectivas de atenção às pessoas com TEA estão surgindo com uma visão mais ampla e descentralizada do foco na criança, trazendo a família como centro de intervenção, olhando, assim, para seus contextos de desenvolvimento e para as pessoas a quem tem relações proximais, para serem mediadores também nesse processo de desenvolvimento.

Muitas pessoas comentam que as pessoas com o TEA ficam no mundo delas, que têm essa dificuldade de estabelecer vínculos mais profundos e parecem não se conectar com o ambiente em que estão. No entanto isso não é bem assim, existe uma tendência de algumas pessoas que, por não conseguirem interagir de forma adequada, acabam mantendo-se mais isoladas ou interagem de forma inadequada.

Talvez as dificuldades de ambientalização das pessoas com deficiência e o olhar para o diagnóstico estejam entrelaçados com sua própria história de exclusão, sendo privados de seus direitos e na mira de pensamentos preconceituosos. Os dois territórios pesquisados já avançaram bastante com políticas, educação, cuidados e atenção para tentar diminuir os impactos sofridos por essas pessoas. Porém ainda há muito o que fazer, diante dos sentimentos que os colocam como incapazes de usufruir das mesmas oportunidades que todos; ainda estão à parte. Para Bauman, estar "[...] deslocado em toda parte, não estar totalmente em lugar algum ([...] sem que alguns aspectos da pessoa 'se sobressaiam' e sejam vistos por outras pessoas como estranho), pode ser uma experiência desconfortável, por vezes perturbadora" (2005, p. 19). 
Nesse sentido, falar do processo de identidade da criança com TEA nos remete a pensar nas infâncias e quanta diversidade está abarcada nesta categoria, necessitando de um olhar ecológico, o qual é possível por meio das contribuições da teoria bioecológica (BRONFENBRENNER; MORRIS, 1998). Esta compreende os elementos envolvidos enquanto pessoa e suas características; o contexto em que o indivíduo se insere; os tempos com as mudanças tanto da pessoa em desenvolvimento quanto na inclusão; e o processo envolvendo as atividades que Ihe são oportunizadas, diante de tantas terapias extras, das quais muitas das crianças com TEA necessitam, já que deve ser estressante para elas se ambientalizarem com tantos estímulos em locais diferentes, com uma carga horária cansativa.

Além disso, estamos acostumados a falar de infância que segue dentro de uma etapa de desenvolvimento que tem uma referência como parâmetro. Falar da infância de uma criança com o TEA requer olhar para a pessoa com suas singularidades e potencialidades, sem o olhar que julga e compara, mas o que acolhe e promove mais experiências de desenvolvimento e autonomia.

Portanto, atualmente, com o aumento de crianças sendo diagnosticadas com o TEA e com o avanço das políticas inclusivas e lutas por direitos dos deficientes, tem se pensado mais sobre a infância da criança com o TEA e os benefícios que a educação pode the proporcionar, sendo garantido por lei usufruir de lugares que são seus por direito. Isso é pensar na importância dos lugares que estamos possibilitando para as crianças desenvolverem-se não só em suas dificuldades, mas na elaboração da própria identidade, enquanto são respeitadas e compreendidas como pessoas. Para isso, pensar em infâncias requer incluir também as que têm deficiências, por meio de um olhar ecológico de possibilidades diante da pessoa.

\section{REFERÊNCIAS}

ASSOCIAÇÃO AMERICANA DE PSIQUIATRIA [AMERICAN PSYCHIATRIC ASSOCIATION]. DSM-5 Manual diagnóstico e estatístico de transtornos mentais. 5. ed. Tradução de Maria Inês Corrêa Nascimento e outros; revisão técnica de Aristides Volpato Cordioli e outros. Porto Alegre: Artmed, 2014.

BACKES, Bárbara; BOSA, Cleonice Alves; ZANON, Regina Basso. Diagnóstico do autismo: relação entre fatores contextuais, familiares e da criança. Revista Psicologia: Teoria e Prática, São Paulo, v. 19, n. 1, p. 152-63, 2017. Disponível em: http://pepsic.bvsalud.org/ pdf/ptp/v19n1/v19n1a09.pdf. Acesso em: 20 set. 2017. 
BOLSANELLO, Maria Augusta.; SOEJIMA, Carolina Santos.; Programa de intervenção e atenção precoce com bebês na educação infantil. Educar em Revista, Curitiba, Brasil, n.43 p. 65-79, 2012. Disponível em: http://www.scielo.br/pdf/er/n43/n43a06.pdf. Acesso em: 19 set. 2017.

BRASIL. Lei n. 13.146, 6 de julho de 2015. Lei Brasileira de Inclusão da Pessoa com Deficiência. Subchefia para Assuntos Jurídicos. Brasília-DF, 2015. Disponível em: http:// www.planalto.gov.br/ccivil_03/_Ato2015-2018/2015/Lei/L13146.html. Acesso em: 15 set. 2017.

BRONFENBRENNER, Urie. Bioecologia do desenvolvimento humano: tornando os seres humanos mais humanos. Artmed: Porto Alegre, 2011.

BRONFENBRENNER, Urie. A ecologia do desenvolvimento humano: experimentos naturais e planejados. Porto Alegre: Artes Médicas, 1996. [Original publicado em 1979].

BRONFENBRENNER, Urie; MORRIS, P. The ecology of developmental processes. In: DAMON, W. (Org.). Handbook of child psychology. New York: John Wiley Sons, 1998. v. 1.

CECCONELLO, Alessandra Marques; KOLLER, Sílvia Helena. Inserção Ecológica na comunidade: uma proposta metodológica para o estudo de famílias em situação de risco. In: KOLLER, Sílvia Helena. (Org.). Ecologia do desenvolvimento humano: pesquisa e intervenção no Brasil. São Paulo: Casa do Psicólogo, 2004. p. 271-95.

CIOLA, Juliana de Cássia Baptistella; FONSECA, Maria Elisa Granchi. Vejo e aprendo: fundamentos do programa TEACCH: o ensino estruturado para pessoas com autismo. 1. ed. Ribeirão Preto, SP: Book Toy, 2014.

CHARMAZ, Kathy. A Construção da Teoria Fundamentada: guia prático para análise qualitativa. Porto Alegre: Artmed, 2009.

COPETTI, Fernando; KREBS, Ruy. Jornada. As propriedades da pessoa na perspectiva do paradigma bioecológico. In: KOLLER, Sílvia Helena. (Ed.). Ecologia do desenvolvimento humano: pesquisa e intervenção no Brasil. São Paulo: Casa do Psicólogo, 2004. p. 67-89.

GOMES, Mário Henrique. Os modelos pedagógicos High/Scope e do movimento da escola moderna propostas de pedagogia diferenciada, Porto: Biblioteca Nacional de Portugal, 2014 [1974]. (Coleção: Prometeu).

JÚLIO-COSTA, Annelise; ANTUNES, Andressa Moreira. Transtorno de espectro autista na prática clínica. São Paulo: Pearson Clinical Brasil. 2018. 
LISBOA, Carolina Macedo; KOLLER, Sílvia Helena. O microssistema escolar e os processos proximais: exemplos de Investigações científicas e intervenções práticas - Ecologia do desenvolvimento humano. São Paulo: Casa do Psicólogo, 2004.

MANTOAN, Maria Teresa Eglér. Inclusão Escolar: o que é? Como fazer? São Paulo: Summus, 2015.

ROGERS, Sally; DAWSON, Geraldine. Intervenção precoce em crianças com autismo: modelo Denver para a promoção da linguagem, da aprendizagem e da socialização. Educar em Revista, Paraná, n. 59, p. 296-7, 2016. Disponível em: http://www.redalyc. org/articulo.oa?id=155044835019. Acesso em: 10 de dezembro de 2018.

\section{Sobre as autoras:}

Carla Coutinho Moser: Mestre em Educação Ambiental pela Universidade Federal do Rio Grande (FURG). Graduada em Psicologia e Licenciada em Pedagogia pela Universidade Federal do Rio Grande (FURG). Professora de rede pública municipal de ensino. E-mail: carlacoutinhom@gmail.com, Orcid: http://orcid.org/0000-0003-2440-976X

Narjara Mendes Garcia: Doutora em Educação Ambiental pela Universidade Federal do Rio Grande (FURG). Pedagoga. Professora Adjunta no Instituto de Educação da Universidade Federal do Rio Grande (FURG). Professora permanente do Programa de Pós-Graduação em Educação Ambiental. E-mail: narjaramg@gmail.com, Orcid: http://orcid.org/0000-0003-0947-6542

Priscila Wally Chagas: Doutora em Educação Ambiental pela Universidade Federal do Rio Grande (FURG). Mestre em Educação. Licenciada em Pedagogia pela Universidade Federal do Rio Grande (FURG). Professora de rede pública municipal de ensino. E-mail: priwallyfurg@yahoo.com.br, Orcid: http://orcid.org/0000-0003-1301-9096

\section{Recebido em 16/04/2019}

Aprovado em: 01/02/2021 
